US Army Corps

of Engineers ${ }_{\circledast}$

Engineer Research and

Development Center

\title{
ERDC
}

CADD Military Direct Program

\section{Alternative Analysis for Construction Progress Data Spatial Visualization}

Jonathan L. Boone, Bobby Sells, Matthew

September 2021

Davis, and Dan McDonald

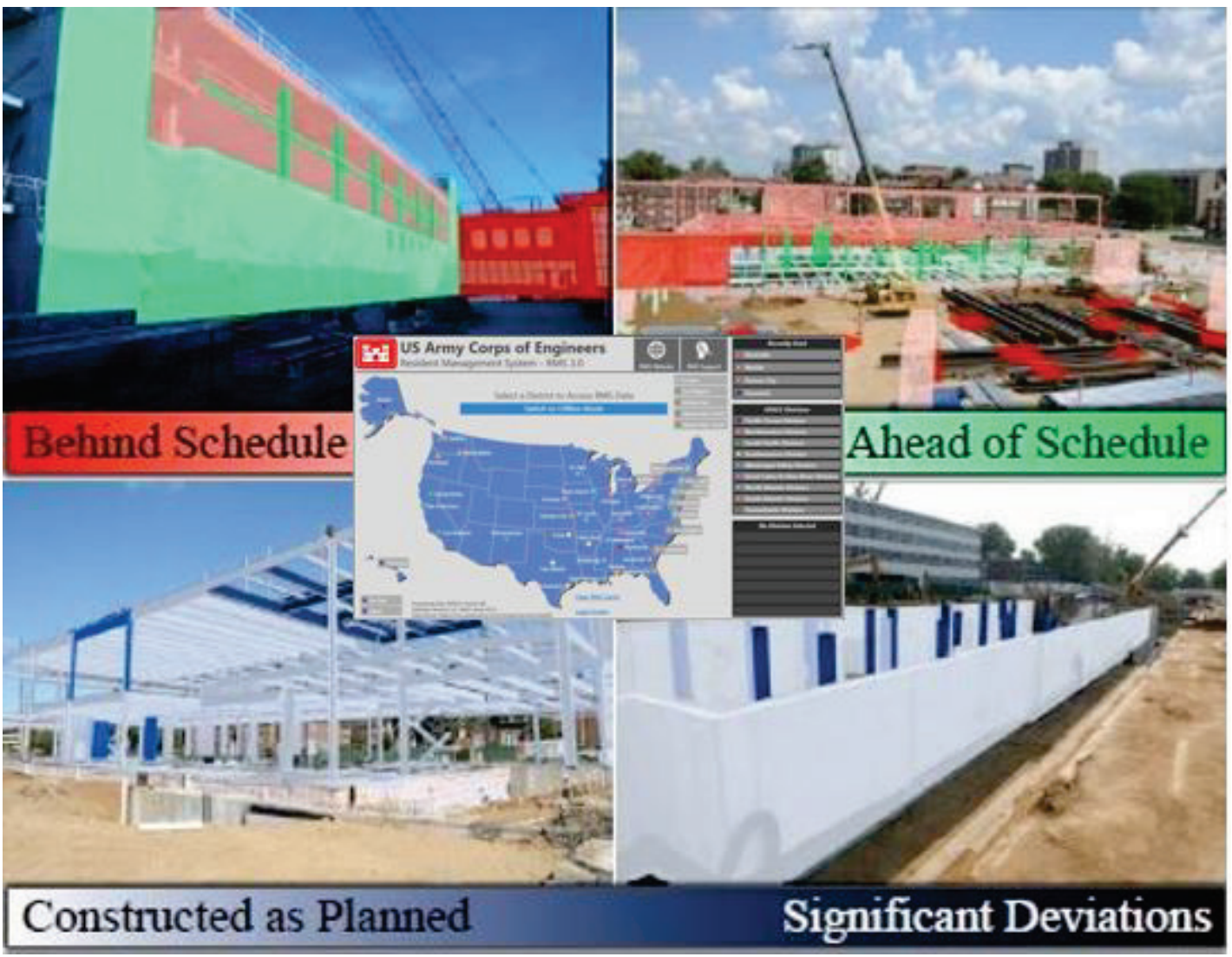


The U.S. Army Engineer Research and Development Center (ERDC) solves the nation's toughest engineering and environmental challenges. ERDC develops innovative solutions in civil and military engineering, geospatial sciences, water resources, and environmental sciences for the Army, the Department of Defense, civilian agencies, and our nation's public good. Find out more at www.erdc.usace.army.mil.

To search for other technical reports published by ERDC, visit the ERDC online library at http://acwc.sdp.sirsi.net/client/default. 


\title{
Alternative Analysis for Construction Progress Data Spatial Visualization
}

\author{
Jonathan L. Boone \\ Information Technology Laboratory \\ U.S. Army Engineer Research and Development Center \\ 3909 Halls Ferry Road \\ Vicksburg, MS 39180-6199 \\ Bobby Sells, Matthew Davis, and Dan McDonald \\ U.S. Army Corps of Engineers, Nashville District \\ U.S. Army Corps of Engineers \\ 801 Broadway A415 \\ Nashville, TN 37203
}

Final report

Approved for public release; distribution is unlimited.

Prepared for U.S. Army Corps of Engineers

Washington, DC 20314-1000

Under CADD Military Direct Program Work Unit, FWIC:673KDK 


\section{Abstract}

The U.S. Army Corps of Engineers (USACE) construction projects have multiple stakeholders that collaborate with project delivery team members during the execution of these projects. Many of these stakeholders are located across the U.S., which makes virtual interactions a common communication method for these teams. These interactions often lack spatial visualization, which can add complications to the progress reports provided and how the information is received/interpreted. The visualization of project progress and documents would be invaluable to the stakeholders on critical projects constructed by the USACE. This research was conducted to determine alternatives for migrating Resident Management System (RMS) data into a portal web viewer. This report provides proposed solutions to creating these links in efforts to better harmonize data management and improve project presentation

DISCLAIMER: The contents of this report are not to be used for advertising, publication, or promotional purposes. Citation of trade names does not constitute an official endorsement or approval of the use of such commercial products. All product names and trademarks cited are the property of their respective owners. The findings of this report are not to be construed as an official Department of the Army position unless so designated by other authorized documents. 


\section{Contents}

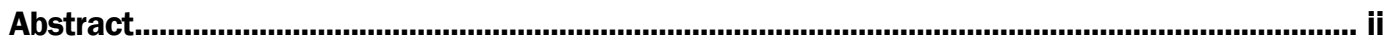

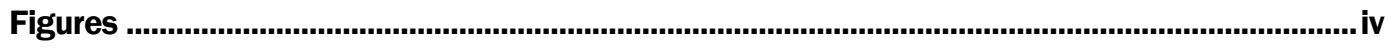

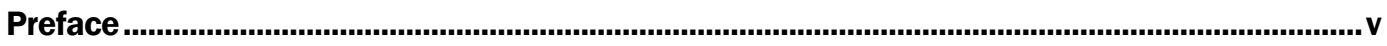

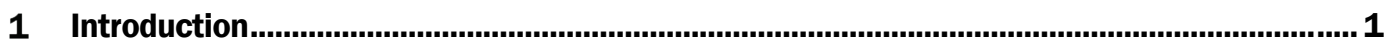

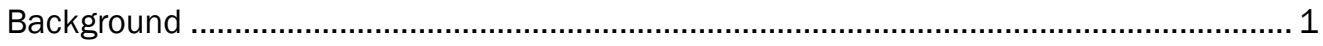

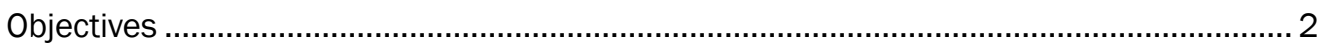

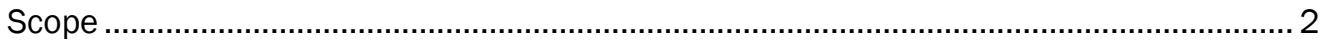

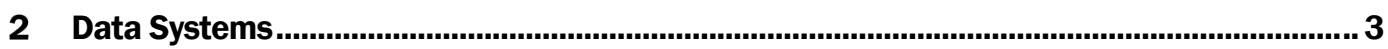

Resident Management System (RMS) background ..................................................... 3

Resident Management System (RMS) data formats ......................................................... 4

Enterprise Data Warehouse (EDW) background.......................................................... 5

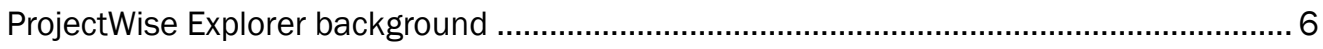

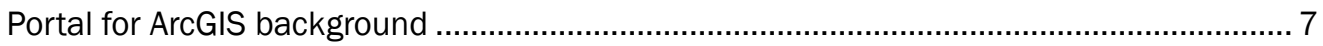

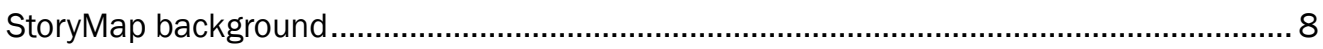

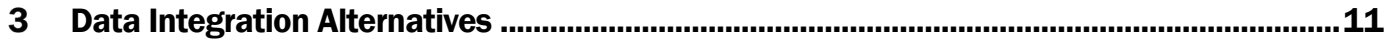

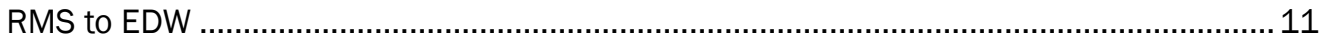

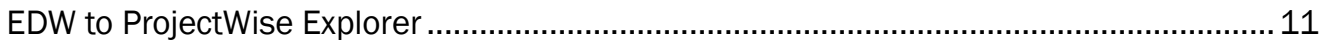

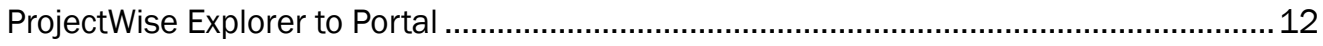

ArcMap Document Hyperlink tool.............................................................................. 12

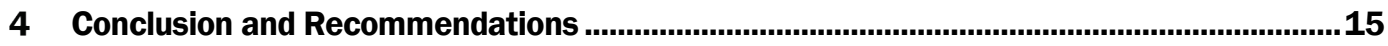

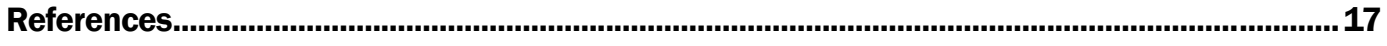

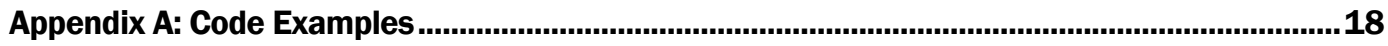

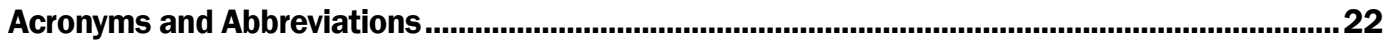

\section{Report Documentation Page}




\section{Figures}

Figure 1. Resident Management System (RMS) user interface. ....................................................... 3

Figure 2. USACE EDW system resources. …………................................................................. 6

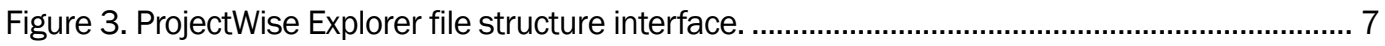

Figure 4. ArcGIS Enterprise Portal for USACE Nashville District's Rough River Project...................... 8

Figure 5. ArcGIS Enterprise Portal for engineering document access. ............................................. 9

Figure 6. Map retrieval of asset documentation. .......................................................................... 13

Figure 7. Legacy inspection documentation for future visual reference.......................................... 14

Figure 8. Data Discovery workflow diagram. ............................................................................. 16 


\section{Preface}

This study was conducted for the Information Technology Laboratory (ITL) under the CADD Military Direct Program, Work Unit FWIC 673KDK. The technical monitor for this program was Mr. Edward Huell.

The work was performed by the U.S. Army Corps of Engineers, Nashville District and the Computer Aided Design/Building Information Modeling Technology Center of the Software Engineering and Informatics Division (SEID), U.S. Army Engineer Research and Development Center, Information Technology Laboratory (ERDC-ITL). Mr. Edward L. Huell, Jr was the Chief of the CAD/BIM Technology Center, Mr. Quincy Alexander was the Acting Chief of the SEID, Ms. Patti S. Duett was the Deputy Director of ITL, and Dr. David A. Horner was the Director of ITL.

COL Teresa A. Schlosser was the Commander of ERDC, and Dr. David W. Pittman was the Director. 


\section{Introduction}

\section{Background}

The critical involvement of the U.S. Army Corps of Engineers (USACE) in construction management documentation of the Nation's infrastructure necessitates research into how to automate a better data management process allowing various disciplines and organizations to maintain knowledge of on-going progress. The purpose of this research is to document the exploration of linking Resident Management Systems (RMS) to other platforms while simultaneously provide proposed solutions to creating these links in efforts to better harmonize data management and improve project presentation. USACE construction projects have multiple stakeholders collaborating with project delivery team members during the execution of these projects. Many of these stakeholders are located across the U.S., which makes virtual interactions a common communication method for these teams. These interactions often lack spatial visualization, which can add complications to the progress reports that are provided and how the information is received/interpreted (Rms.usace.army.mil). The visualization of project progress and documents would be invaluable to the stakeholders on critical civil works infrastructure constructed by the District team. It is important to note that there were several different mediums researched on how to access, store, and serve this data to a portal. They include RMS, Enterprise Data Warehouse (EDW), ProjectWise, Internet Information Services (IIS) directory, and Environmental Systems Research Institute (ESRI) Data Store.

The research explores the feasibility and functionality to provide project tracking, assist with briefings, and provide for easy overall project awareness. Utilizing both $2 \mathrm{D}$ and $3 \mathrm{D}$ applications will give the entire project delivery team a new perspective on in-progress reviews. The document linking process will allow users to pick individual features to focus on and see all accompanying documentation including reference documents, pictures, video, drawings, and other construction data.

This research aims to provide the optimal process, which provides no data duplication, support database document retrieval, and hosting of Representational State Transfer (REST) services with attachments. RMS 
stores all project related construction documents and contract communications with the contractor. This data is not currently available in a geospatial web environment.

ArcGIS Portal was investigated for compatibility with RMS CLOB/BLOB data. Portal takes advantage of an existing Enterprise License Agreement between the ESRI and USACE. ESRI Portal allows for orderly hosting of geospatial web applications with big datasets.

IIS Web Directories were researched for their ability to effectively compress, host, index, and serve this data. Challenges encountered with IIS were space, permissions, maintenance, and management. This is the simplest commercially available software; however, it requires knowledge of the Windows server environment. This alternative also duplicates big data and requires knowledge of setting up network shares and deploying web directories.

ProjectWise was also examined due to the arduous process of copying files down for importing of RMS data. ProjectWise is the storage medium for Government project plans and specification. This process could run secondary to the process of attaining the files from RMS. ProjectWise web Application Program Interface (API) was researched for the ability to host geospatial attachments. The Districts have control of their implementation of the ProjectWise structure, which makes scripting increasingly possible.

\section{Objectives}

This research is necessary to improve construction progress data spatial visualizations for USACE construction contracts and to make the project information more accessible by the project stakeholders.

\section{Scope}

The scope includes exploring the capability of linking the RMS construction database into an ArcGIS Portal web-based viewer. This research documents the exploration of linking the RMS data to other platforms that will harmonize data management visualization and improve project communications with stakeholders (Stumpf et al. 1995). 


\section{Data Systems}

\section{Resident Management System (RMS) background}

The RMS is designated as the USACE standard construction management information system. It focuses on the construction phase of project management and provides comprehensive support for construction managers. RMS is a quality management and contract administration system designed by a Resident Engineer to help the staff complete their mission (Figure 1). The system provides an efficient method to plan, accomplish, and control contract management by integrating job specific requirements, corporate technical knowledge, and management policies (Chin 1995). RMS allows front-line field personnel to concentrate on their primary functions, such as on-site quality assurance, customer care, preparation of modifications, safety regulations, etc., while accomplishing routine administrative tasks (Chu 1995).

Figure 1. Resident Management System (RMS) user interface.

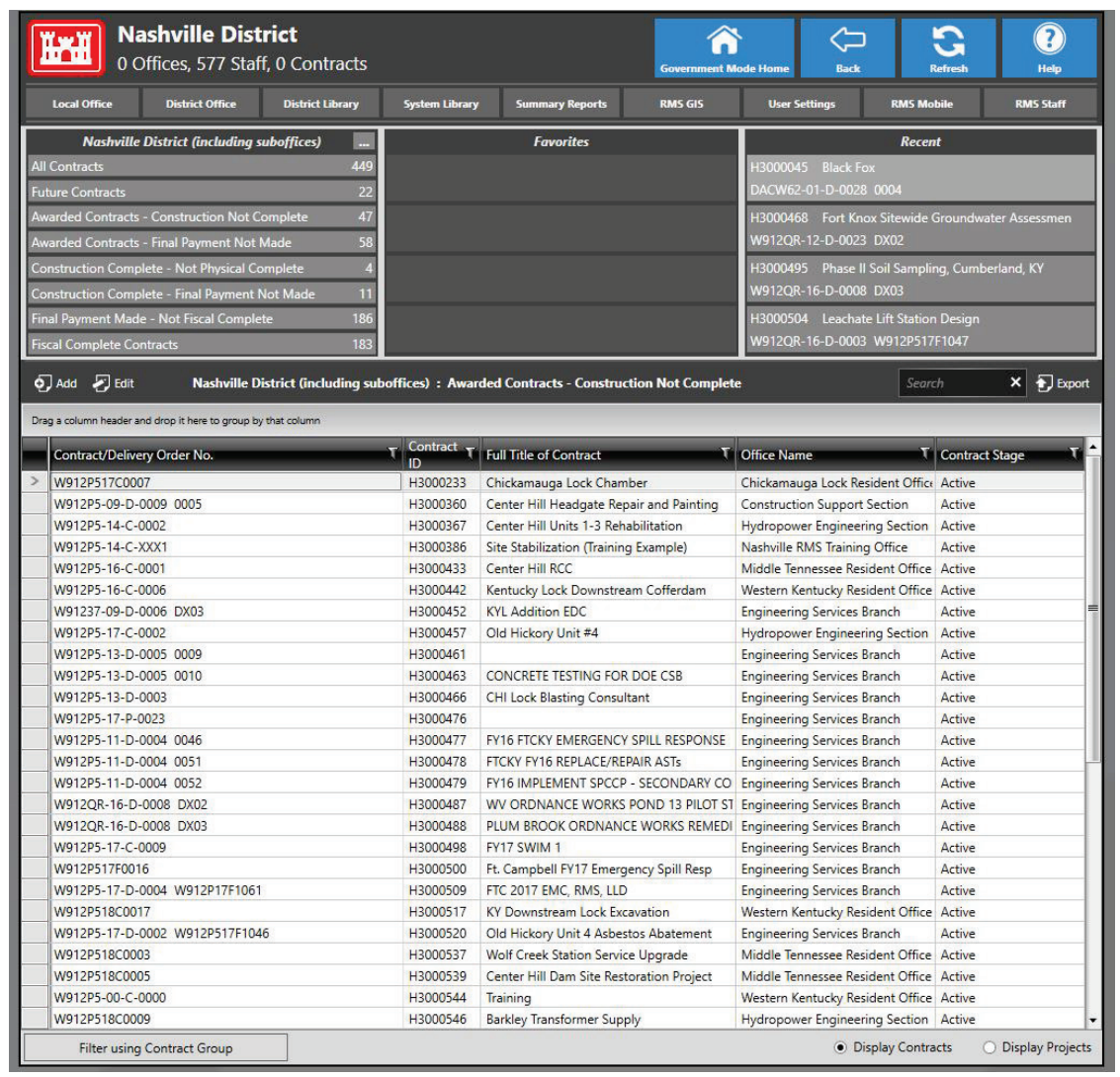




\section{Resident Management System (RMS) data formats}

RMS runs on an Oracle 12c database. Forms, documents, drawings, comments, etc. are stored in either a Character Large Object (CLOB) or a Binary Large Object (BLOB) format in the database, which can be exported to other databases. CLOB/BLOB data definitions and information include: BLOB is for binary data (videos, images, documents, other) and CLOB is for large text data (text) (USACE 1993).

CLOBs are used for semi-structured data and include document files such as XML documents or word processor files. These files contain data in a logical structure that is processed or interpreted by an application and is not broken down into smaller, logical units when stored in the database (Barker 1991).

Applications that use semi-structured data often use large amounts of character data. The CLOB data type is ideal for storing and manipulating this kind of data. BFILEs (LOB datatype that can be access directly from the operating system) can be used to load read-only data from operating system files into CLOB or National Large Object (NCLOB) instances that could then be manipulated in the application.

BLOBs are used for unstructured data, which is data that cannot be decomposed into standard components. This is in contrast to structured data, which contains easily identifiable components: a name that is stored as a string, an ID number, a start date, etc. Unstructured data, such as a photograph, consists of a long stream of 1 s and os. These bits are used to switch pixels on or off so the picture can be seen on a display, but the bits are not broken down into any standard components for database storage. ${ }^{1}$

Similarly, other unstructured data such as text, graphic images, still video clips, and full motion video tends to be large in size. A typical project record may be a few kilobytes, while even small amounts of multimedia data can be thousands of times larger. Oracle data types that are ideal for large amounts of unstructured binary data include the BLOB data type. ${ }^{2}$

\footnotetext{
1 https://community.oracle.com/message/14173350\#14173350

2 https://docs.oracle.com/en/database/oracle/oracle-database/19/adlob/securefiles-and-largeobjects-developers-guide.pdf, September 2019
} 
This data can be accessed externally by query with procedures written in Java, JavaScript, PL/SQL, or Apex (appendix A). These languages were researched, but other scripting languages could be utilized for development to execute against the database. The resulting output could be cast into another database, IIS, ProjectWise, or other flat file system. ${ }^{1}$

The stream procedure provides the means to put those CLOB/BLOBs into another medium. The query script will need many qualifying attributes to limit the records returned and "overloading" the system, which could result in instability, overuse of system resources, data corruption, or data loss. These queries would be written with a structure that identifies documents for targeted project/contract, query that result with a date query, query that result with a type, etc. This structuring pulls a limited/smaller number of documents using the query attributes themselves to assist in locating the files within the directory structure.

\section{Enterprise Data Warehouse (EDW) background}

The EDW provides USACE with a single repository for instant access to highly shared data, which would support more informed decision making (Figure 2). The benefits are as follows; single source for coded and ad hoc analytical reporting, immediate information delivery, data integration across organizations from internal and/or external sources, historical data and trend analysis, and standard reporting toolset that supports looking at information in new ways. EDW access is controlled and requires special privileges to access.

\footnotetext{
1 https://stackoverflow.com/questions/42244941/how-to-export-clob-field-datas-in-oracle-sql- 
Figure 2. USACE EDW system resources.

\section{USACE Enterprise Data Warehouse}

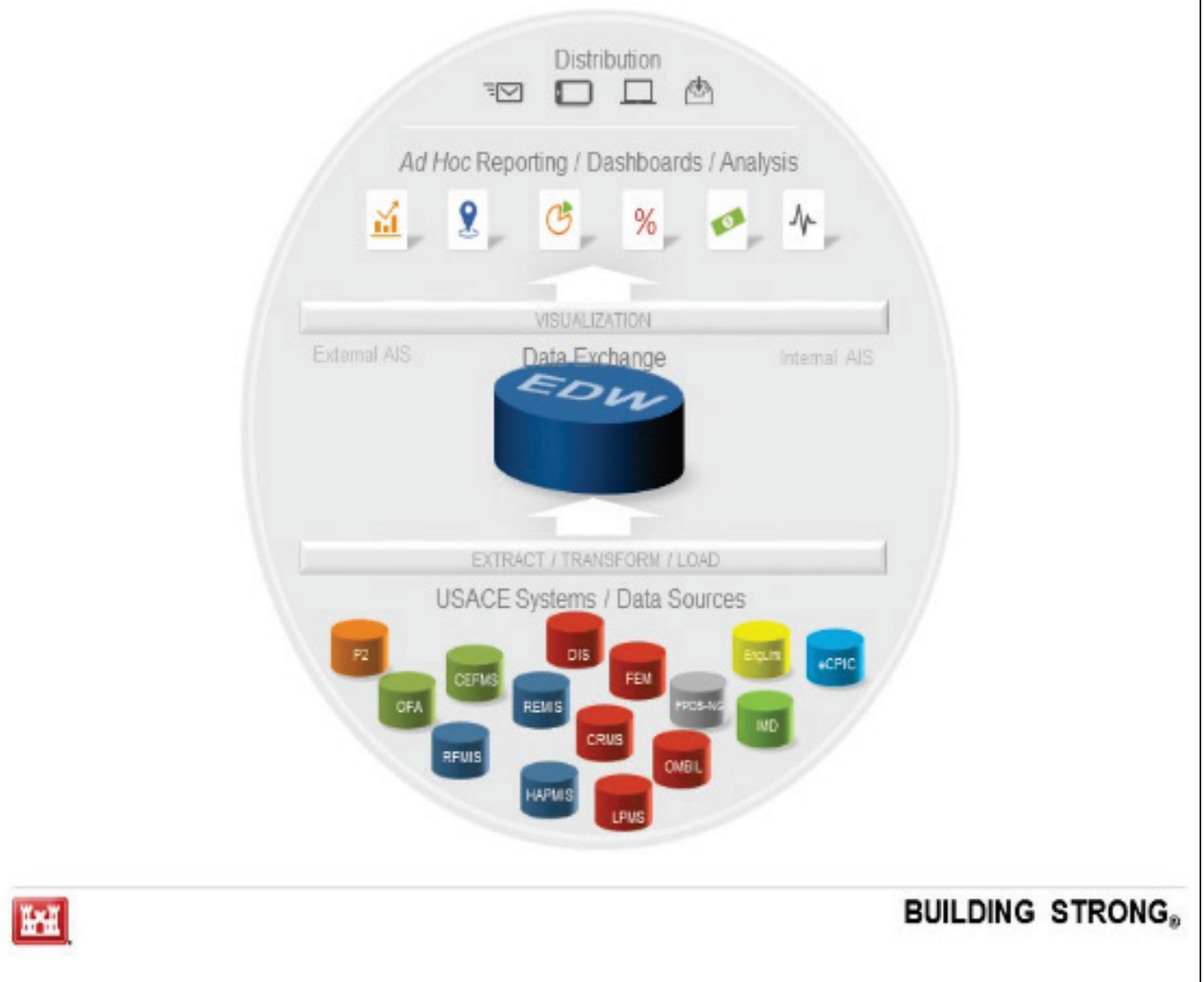

\section{ProjectWise Explorer background}

Bentley ProjectWise Explorer is a robust engineering document management system that allows for management of project-related data and information locally and regionally (Figure 3). The benefits of using ProjectWise as the data repository are promoting virtual team's collaboration across USACE Districts, common data storage and access, searchable documents to find pertinent information quickly, and documents can be set to read only to preserve the data. 
Figure 3. ProjectWise Explorer file structure interface.

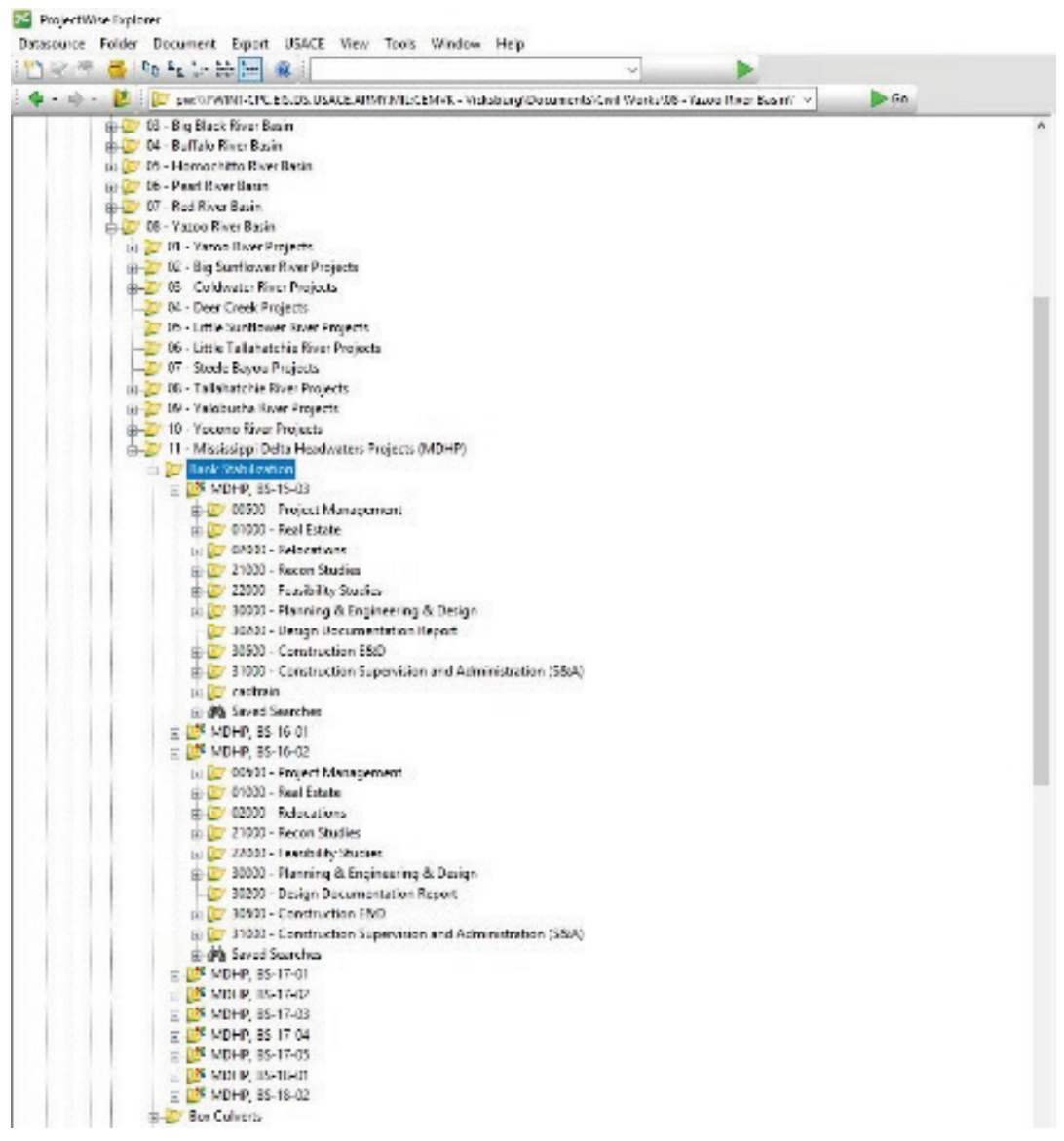

\section{Portal for ArcGIS background}

Portal for ArcGIS is an enterprise application created for geospatial cloud computing. Portal is highly customizable and can be completed with no programming. The ESRI staff stated, "The best option to host these documents is with ESRI big data store and Azure." USACE has several pilot projects underway to determine the viability of Microsoft Azure. Using a data store for applying geospatial geometries and providing viewing capabilities would allow for exporting data and performance monitoring. Whether data is hosted in a data store, geospatial database, database, or IIS web directory, Portal services can display it, unless it is a BLOB/CLOB stored outside of ESRI Data Store. Portal and its accompanying visualization tools do not allow for direct visualization of CLOB/BLOB data. 


\section{StoryMap background}

StoryMap is a geospatial mash-up environment that can incorporate intelligent web maps with multimedia applications that can be linked to features on a map (Figure 4 and Figure 5).

Figure 4. ArcGIS Enterprise Portal for USACE Nashville District's Rough River Project.

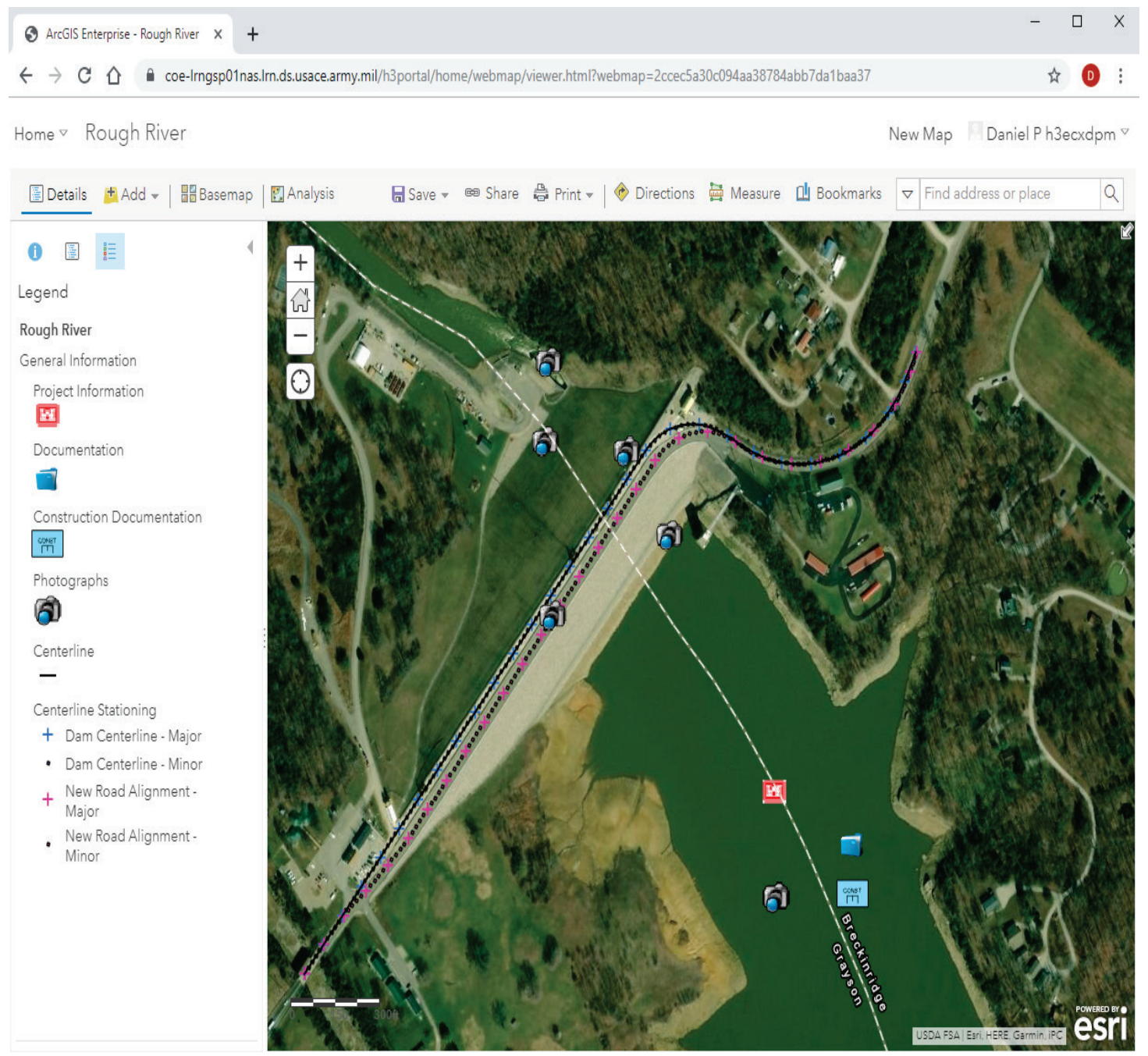


Figure 5. ArcGIS Enterprise Portal for engineering document access.

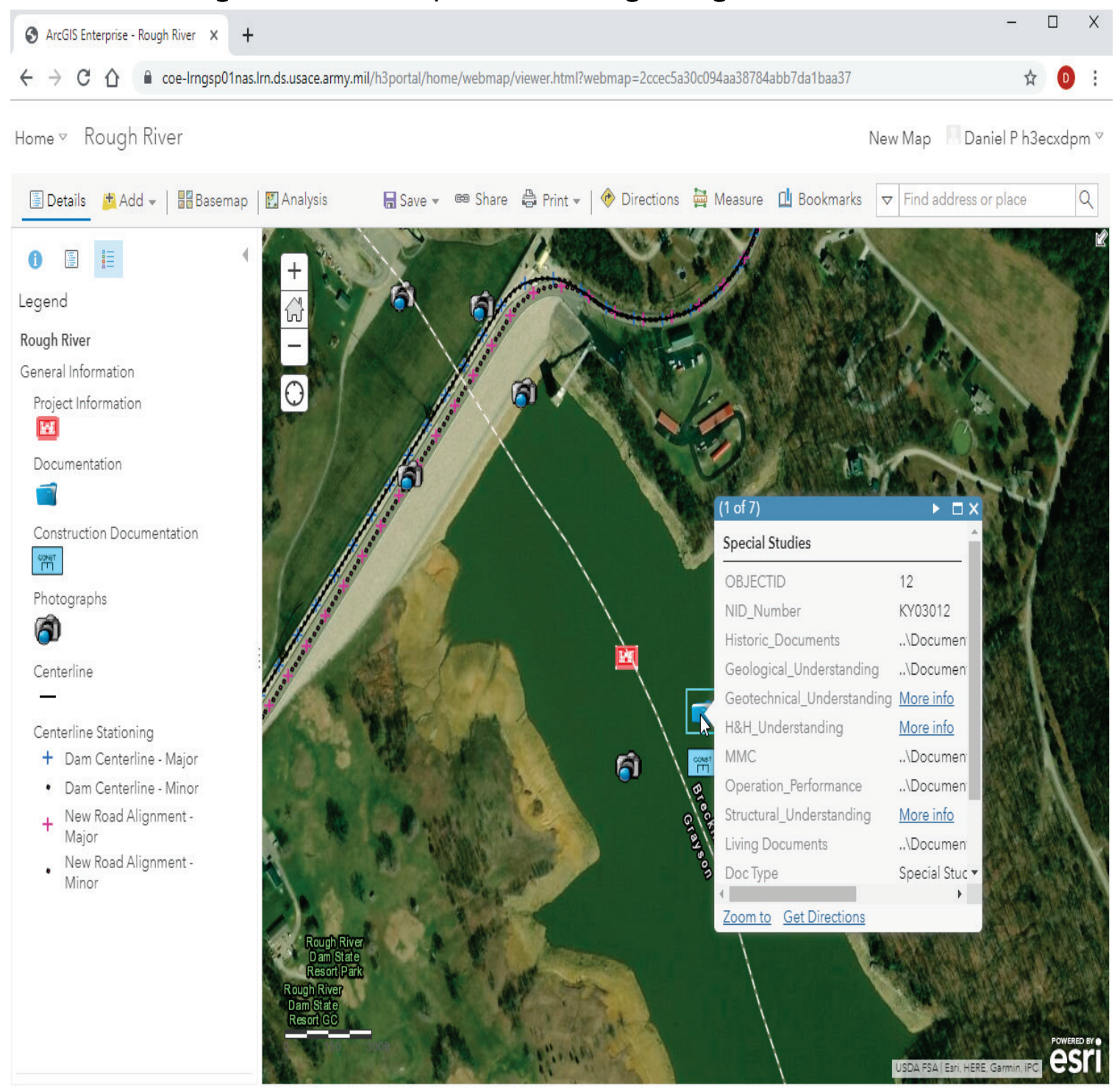

StoryMaps intuitively displays individual features/data at any depth of detail while simultaneously facilitating discussions with the map's functionality. The RMS data is no different; one could have a StoryMap that shows the location of the project via the map with any multimedia data types including air photos, as-builts, photos of the structures, contract specifications and/or budgetary information if available.

In short, any USACE business line can be developed into a StoryMap environment including the aforementioned map and multimedia functionality. The genuine benefit of the StoryMap involves taking all the RMS project components in their entirety and showing them holistically as an overview. 
The working viewer that would be developed in ESRIs Portal application would allow the clicking of any feature to return the associated RMS documents for review, verification, and discussions. 


\section{Data Integration Alternatives}

\section{RMS to EDW to ProjectWise}

Limited RMS data is extracted from EDW for future ProjectWise implementation using the RMS REST API, but not for CLOB/BLOBs. An alternative option for data extraction could ultimately be fielded, but this is a direct duplication of data. Considering the potential file sizes, EDW would have to be consulted about potential. The lack of existing data and the potential issue of file sizes makes this alternative the least attractive.

\section{EDW to ProjectWise Explorer}

As described above, the EDW solution is at present incomplete and will present many hurdles to overcome per the EDW staff. Although the file sizes will need to be examined more closely to understand viability. This is by far the simplest solution on the surface. For this to be effective, many attributes will have to be accessed from the current database to render the file to its native format. The renderer will need to attempt rendering in a pre-formatted list of extensions. Once rendered, they will be placed in folders built with fields and attributes derived from RMS.

Directory browsing allows users of the web app to see a directory listing and files within a specified directory. Directory browsing is disabled by default for security reasons. Enable directory browsing by invoking the Use Directory Browser method in the Startup and Configure menus. Static File Middleware understands almost 400 known file content types. If the user requests a file with an unknown file type, Static File Middleware passes the request to the next middleware in the pipeline. If no middleware handles the request, a 404 Not Found response is returned. If directory browsing is enabled, a link to the file is displayed in a directory listing. This link would have to be added to feature attachments. This process would allow for scripting to identify the project folder structure and insert the CLOB/BLOB data.

Putting these documents into ProjectWise would answer the question of where to store the data, which is moved over by engineers working on the project. The ProjectWise option would also require some exposure to the database to allow for the relocation. Getting from ProjectWise to the web 
would require the installation of ProjectWise web API and research of hosting files without creating a check in and out procedure.

\section{ProjectWise Explorer to Portal}

Once the decision is made about where to get and put the data, assigning the geospatial location is the next step. There already exists a previously developed tool to assign these attachments, which will be discussed later in the document. Once there, it will be built into the data store of ArcGIS Portal and will be hosted as feature layer attachments. One of the most important questions to be answered by data administrators has to do with duplicate data. These extracted files are in the multiple gigabyte (GB) size range. That means the duplication of these files will require a destination that can support them. Spatial Temporal Big Data Store (a product update of the ArcGIS Data Store) is being investigated for the option that duplicates the data. The big data store allows for the effective hosting of rapidly changing, streaming instrumentation, big raster collections, and CLOB/BLOB.

Currently, there is a major issue connecting RMS and ProjectWise and thus USACE staff cannot collaborate in RMS. The workaround has been exporting documents to ProjectWise and then collaborating within that environment.

\section{ArcMap Document Hyperlink tool}

The ArcMap Document Hyperlink tool is used to insert a Document's Hyperlink from ProjectWise Projects into a feature in an ArcMap project. This is done with an ESRI Add-In tool. The document being hyperlinked comes from a document uploaded into the ProjectWise application. The hyperlink is inserted into a feature table.

On first load, the tool will look for any ProjectWise projects found within the ArcMap file already. If there is one found, it will load the documents from that project into the tool so the user can select them to be hyperlinked. If no project is found, one must be opened.

The user will press the Hyperlink Document tool to add hyperlinks to the features, then select the pages in the document and insert a hyperlink into that feature. If there are multiple hyperlinks, the tool will assist the user in overwriting or adding a new Hyperlink Column. These hyperlinks are 
added for viewing pertinent contract information in an ESRI Portal application, which displays the information associated to the USACE project being completed with a pop-up tool.

Because of the nature of these documents, they are a mixture of current and legacy information and only have a unique ID as an identifier. Because of this limitation, the documents need to be handled on a case-bycase basis and organized into their respective projects. Before starting the task of creating hyperlinks, the RMS data needs to be completely organized.

Once the RMS data is organized into projects, the hyperlink creation process can be started. Figures 6 and 7 show features on the map and returning documents for reference.

Figure 6. Map retrieval of asset documentation.

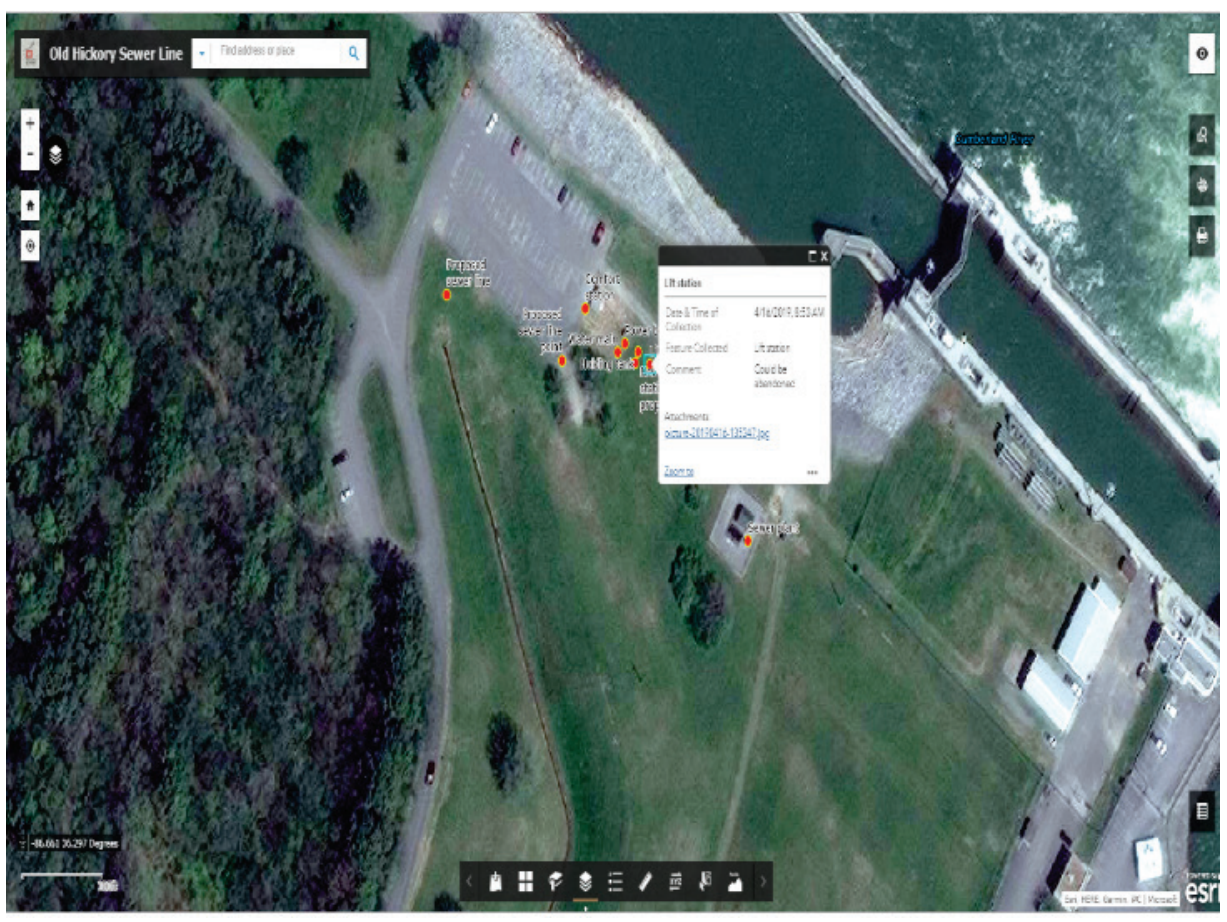


Figure 7. Legacy inspection documentation for future visual reference.

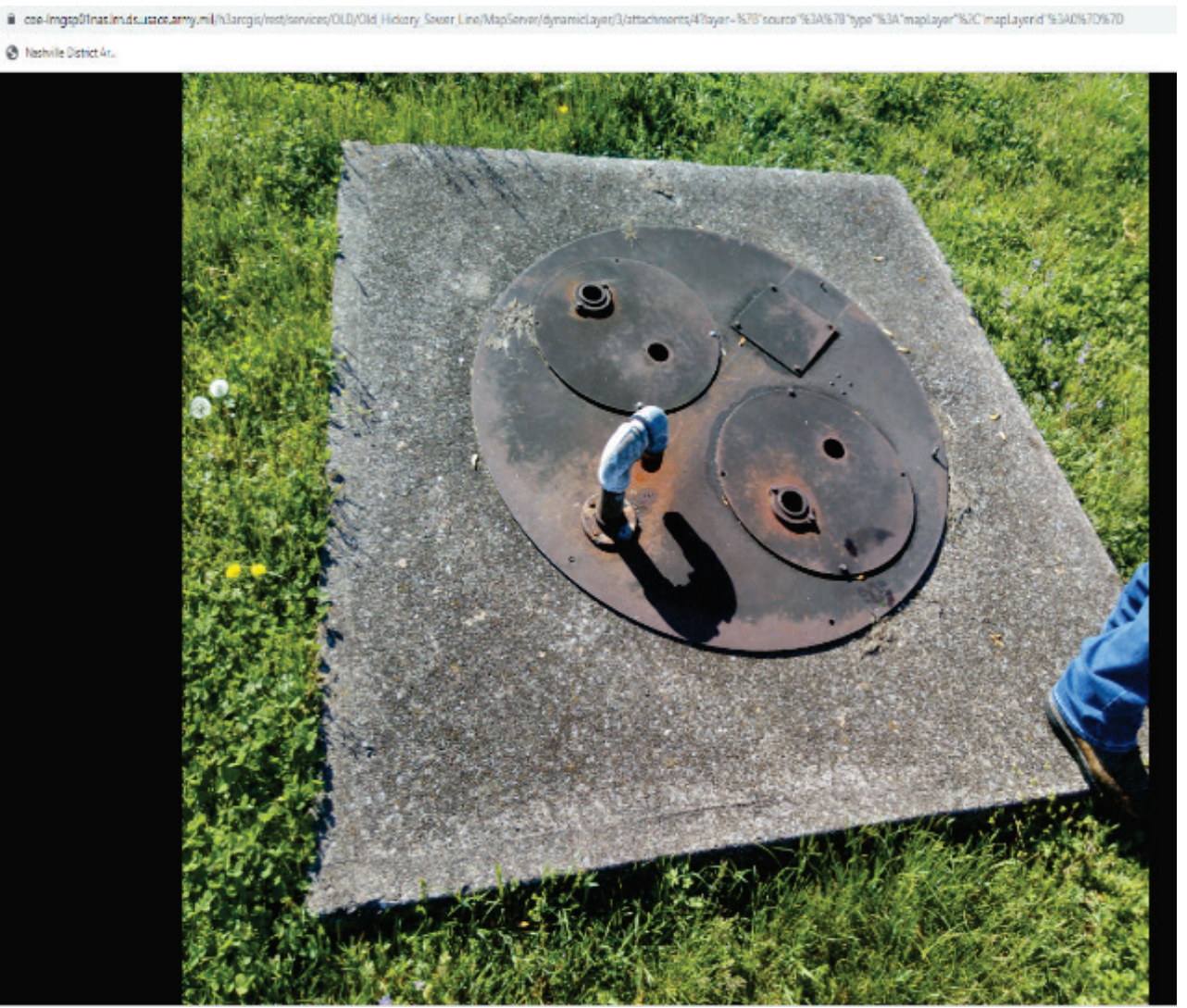




\section{Conclusion and Recommendations}

RMS data cannot be migrated into Portal, natively or directly. Using python, php, or other scripting languages, code can be developed to query and expose CLOB/BLOBs. Apex is an Oracle web development tool that will expose the BLOB natively and this would be the time to move to ProjectWise. At the time of exposure, a push method to place the data into ProjectWise would be activated. Once into ProjectWise, deploy ProjectWise web exposing the web file data storage and hosting. Getting into Portal application will be easiest with a BLOB export to file and data put into a web directory whether it is ProjectWise or IIS.

An implementation trajectory of CLOB/BLOB exposed with apex, copied and stored to ProjectWise, and ProjectWise web API utilized to host document hyperlinking is the path of least resistance to access the data. The most efficient migration method would be coordinated data dumps. Utilizing the coordinate tools will allow for geo-referencing of pictures, documents, pdf's, etc.

The process to make that data visible will require a significant effort in programming. Through research, it was found that getting uniform resource identifiers from the database would allow for display in html, however this is not recognizable as attachments in Portal. Challenges faced doing this: service account to access data, a big percentage stored in zip files and would have to be unzipped with code, BLOB type, and finally rendering within Portal. After many discussions with ESRI support personnel and web research, this is not currently possible within Portal. RMS to EDW was considered to store documents because they have space that could be utilized. This is still a viable option, but not the recommended path. RMS to ESRI data store was investigated and does allow for storage and serving those files natively. This option provides the best connectivity and inclusion in Portal. Challenges include setting up new storage for data store, management and maintenance of data store. RMS to ProjectWise was considered for this data because it is already being manually put into ProjectWise. This process is long and arduous, typically requiring a significant portion of an employee's labor. Nashville District's Civil Design Section's how-to document has been included (Figure 8). ProjectWise is a flat file storage system and can be exposed utilizing ProjectWise web server. After researching all paths available, the most favorable is RMS to ProjectWise. This path affords for labor 
reductions moving files, exposure of data in its native format on the web, and flat file storage allows for the data to be utilized outside of a Portal application. The ArcMap Document Hyperlink Tool was researched for its ability to get ProjectWise data and link them. This tool will improve the process of hyperlinking as it allows for report individual page linking, document linking, image linking, etc. Lastly, story maps were examined as a useful Portal-based tool that would display all of the data for an individual project, contract, etc. Story maps provide a clean way to visualize this data in context but requires labor effort to create those projects.

Figure 8. Data Discovery workflow diagram.

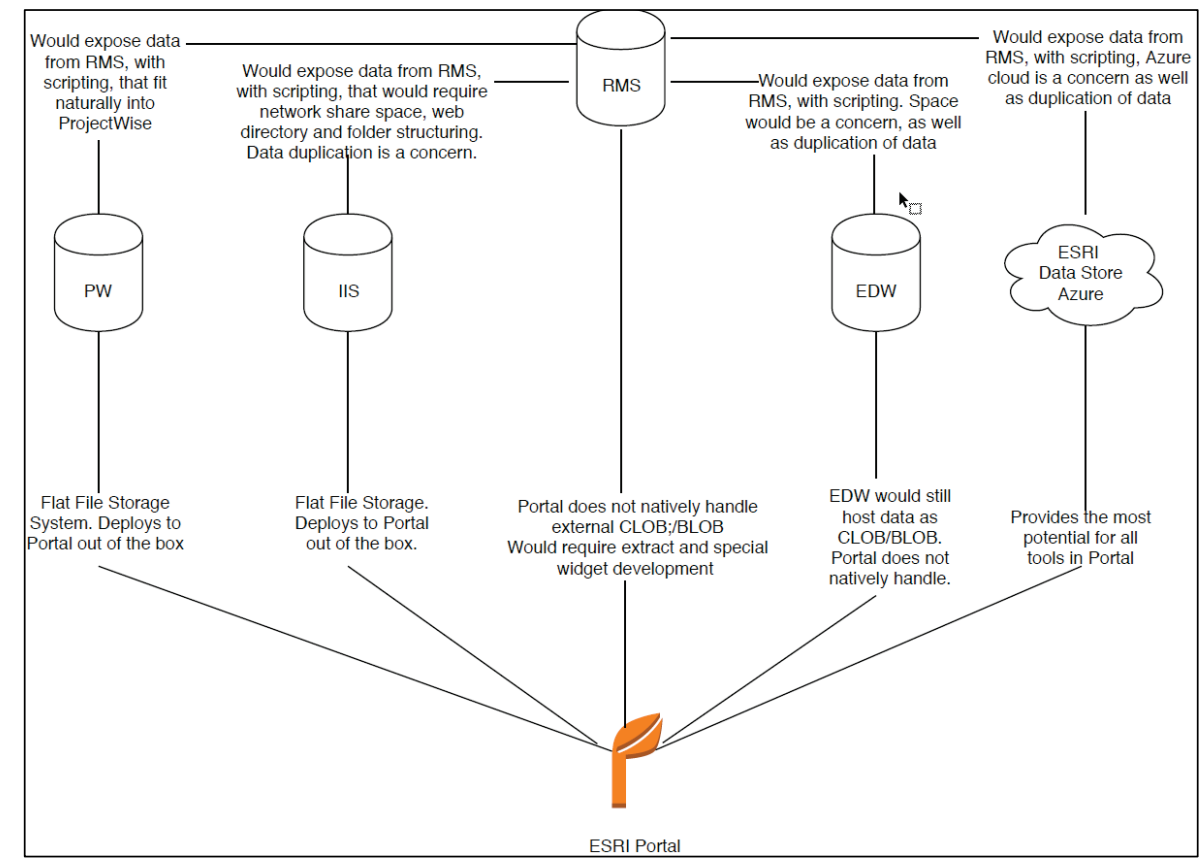

Figure 9: Trajectory of RMS implementation with APEX

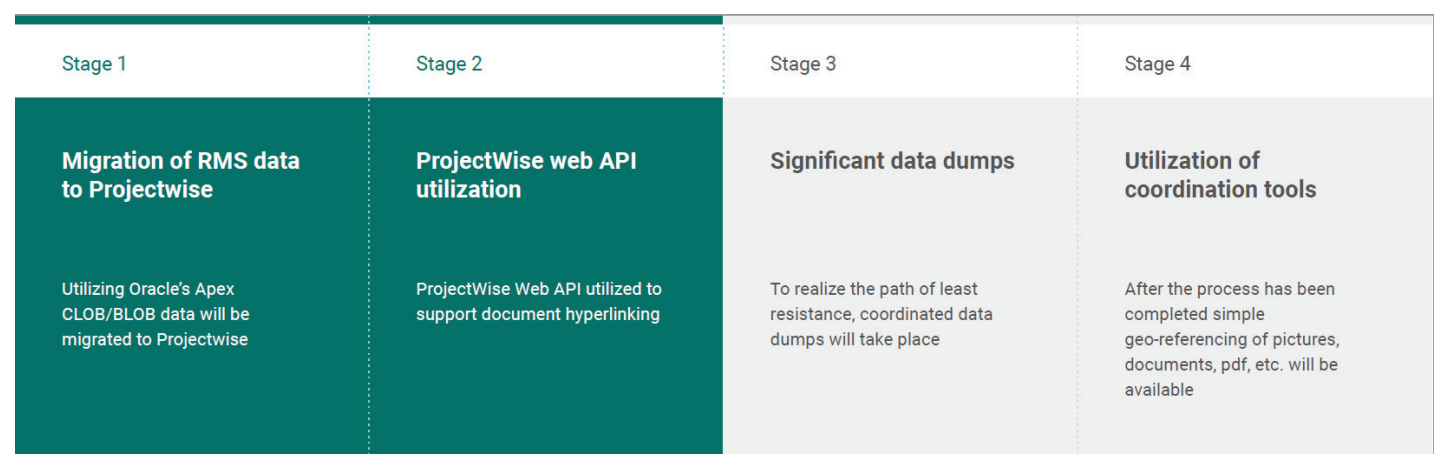




\section{References}

Barker, L. H. 1991. Resident Management System (U.S. Army Corps of Engineers [USACE], Los Angeles District).

Chin, S., L. Y. Liu, A. L. Stumpf, R. Ganeshan, and D. Hicks. 1995. "CADD-Based Construction Information Management for Corps of Engineers Projects." Proceedings of the Second Congress on Computing in Civil Engineering.

Chu, D., A. Stumpf, L. Liu, and S. Chin. 1995. "Construction Quality Assurance in Corps of Engineers Projects Utilizing CADD Systems." Construction Congress, Proceedings of the 1995 Conference, San Diego, CA.

Stumpf, A. L., S. Chin, L. Y. Liu, and R. Ganeshan, 1995. "Use of a Relational Database System to Integrate Product and Process Information during Construction." Modeling of Buildings Through Their Life-Cycle, CIB Proceedings Pub. 180, 21, Stanford University, CA.

Stumpf, A. L., L. Y. Liu, S. Chin, and K. Ahn, 1994. "Using CADD Applications to Support Construction Activities." Proceedings of the First Congress on Computing in Civil Engineering. 


\section{Appendix A: Code Examples}

For display of data, identification and extraction of data, data display. Identify CLOBs and BLOBs:

- Simple query to return files, file dates, type of files.

select FILE_DATA, FILE_DATE, FILE_TYPE FROM RMS_FILES

WHERE OFFICE_ID LIKE 'Hㅇ'

The following code enables serving unknown types and renders the unknown file as an image (also deemed unsafe):

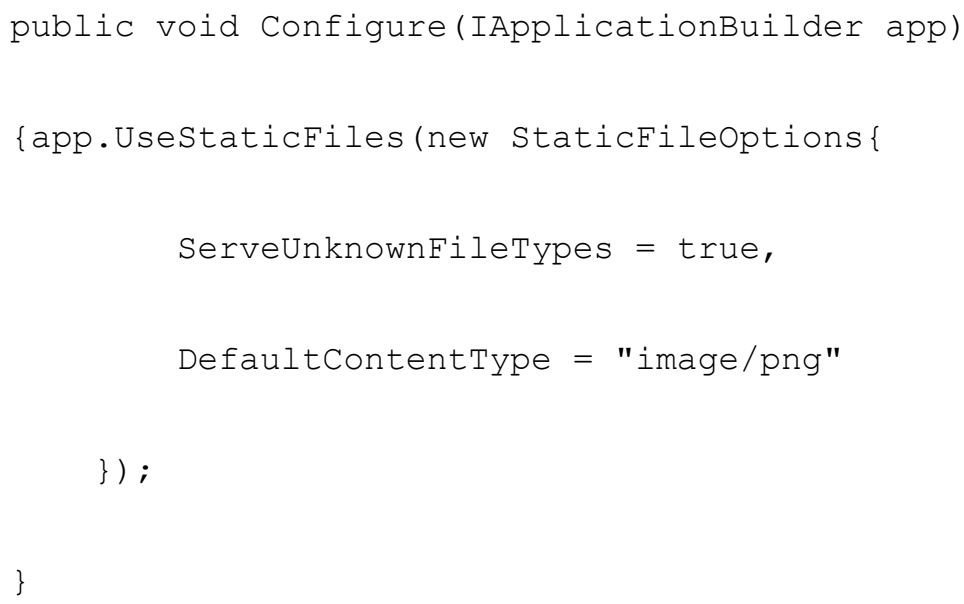

This query would return location, sizes, types and get CLOB/BLOB.

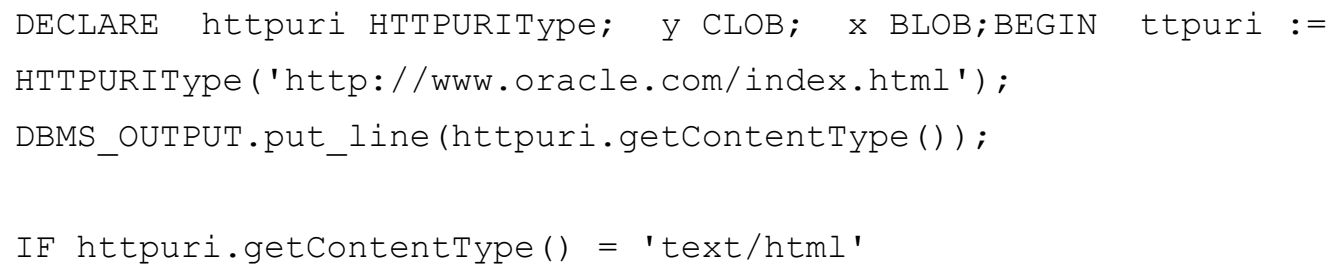




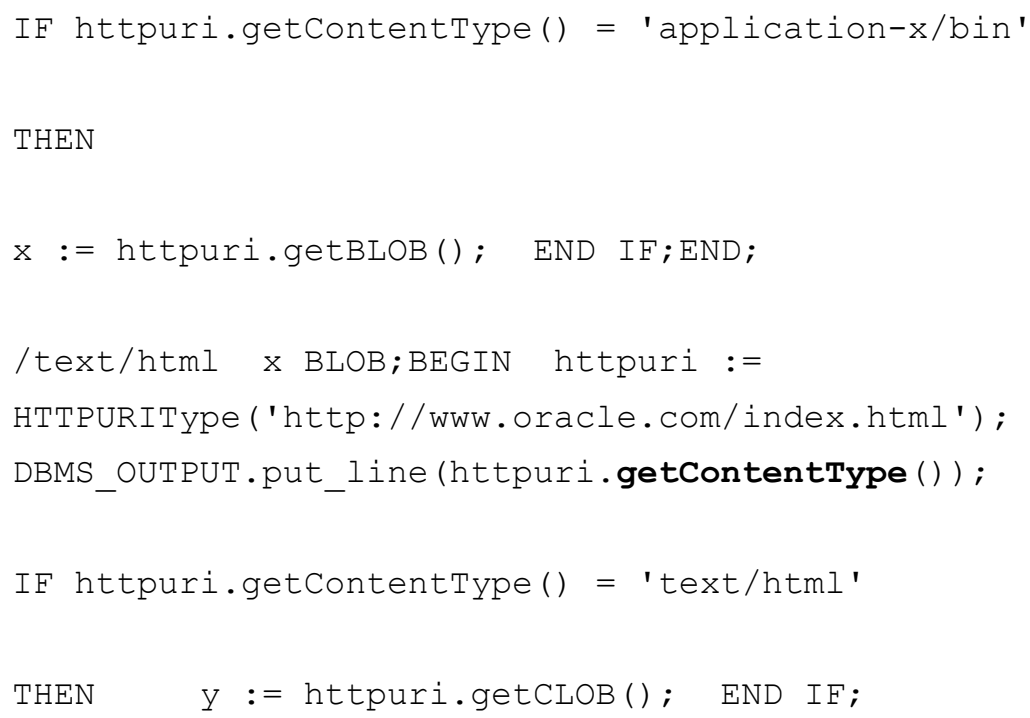

Tried to identify BLOBs in RMS FILES that were low enough to fit under the 4,000 byte maximum of varchar2

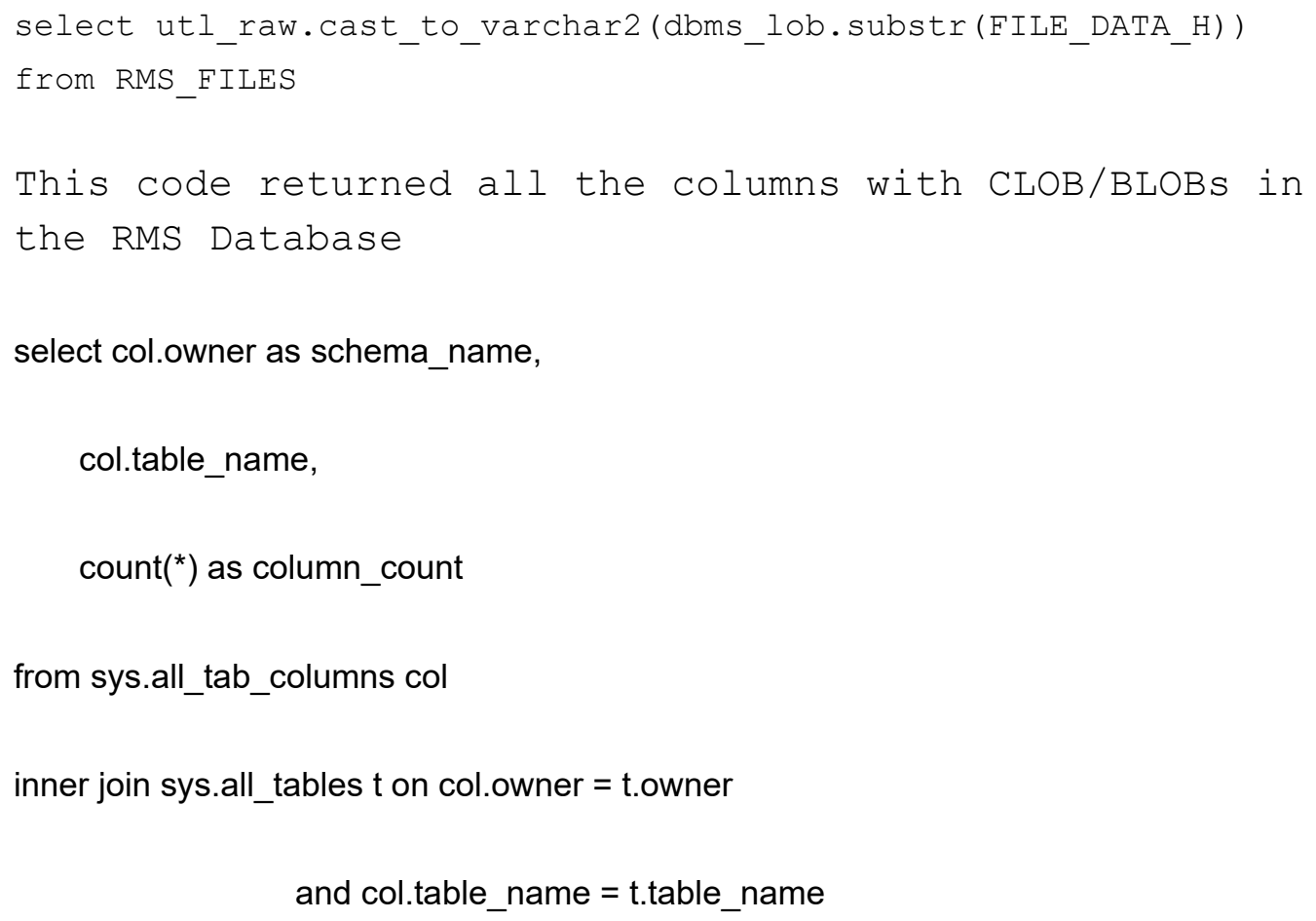




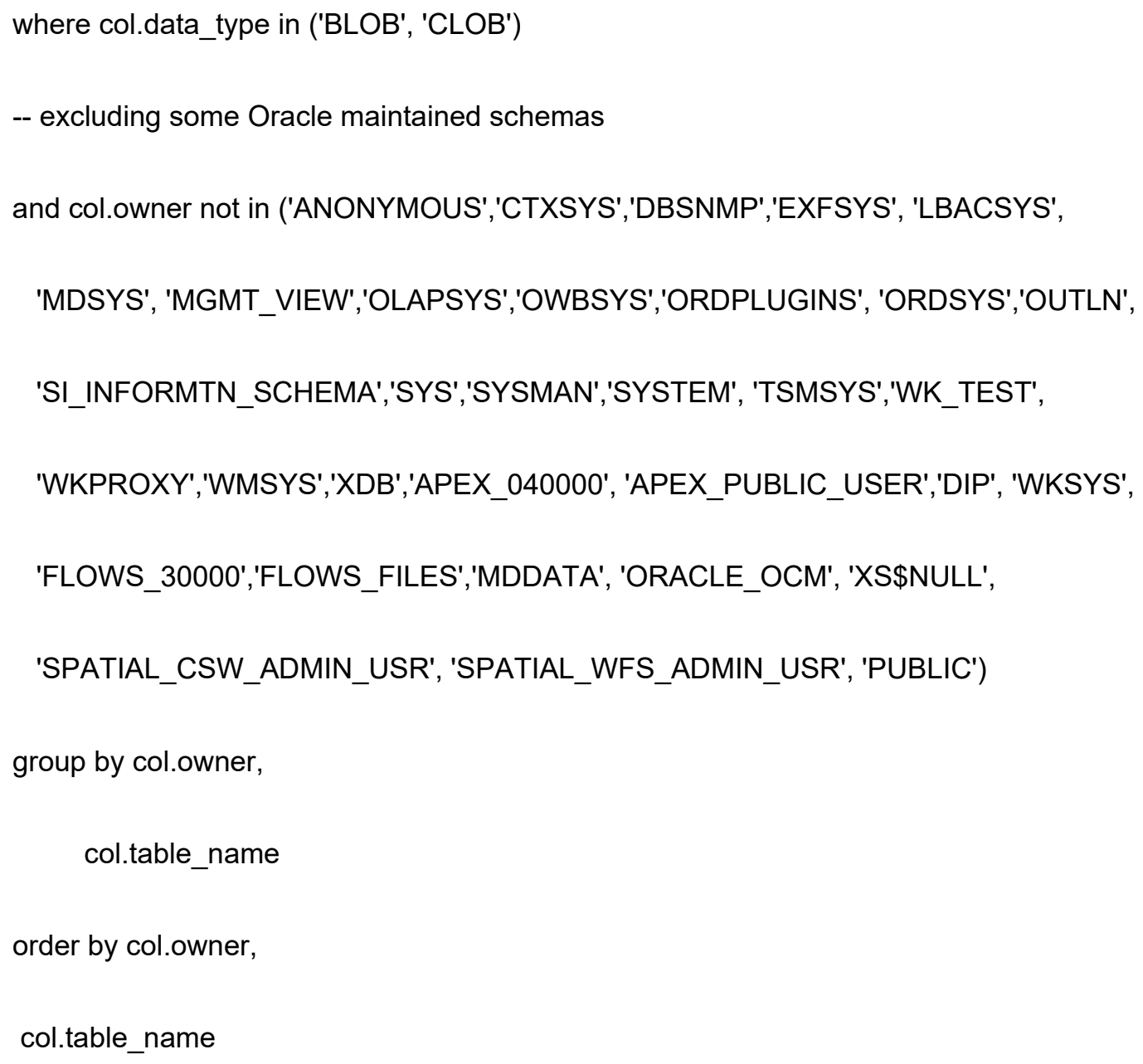

This code snippet returned all of the CLOB/BLOB information to include, table name and column count for the whole database. 


\begin{tabular}{|c|c|c|c|}
\hline Table Name & LOB COLUMN COUNT & Table Name & columncount \\
\hline ACCIDENT & 1 & RB_ITEM_Q & 1 \\
\hline AE_EVAL & 2 & RB_VIEWS & 1 \\
\hline AHA_HAZARD & 1 & REAL_PRO & 1 \\
\hline CACHE_DATA & 1 & RECORD_ATTACHMENT_CONTRACT & 3 \\
\hline CACHE_REQUEST & 2 & RECORD_ATTACHMENT_DISTRICT & 3 \\
\hline CACHE_REQUESTV2 & 2 & QCI_TRANSMIT_REMARKS & 1 \\
\hline CACHE_REQUEST_PART & 1 & QCQA_COM & 1 \\
\hline CHECKS & 3 & QC_REQUIREMENTS & 2 \\
\hline CHECKS_M & 2 & QDD & 1 \\
\hline CONTRACT & 2 & QDS & 1 \\
\hline CONTRACT_ARCHIVE & 1 & QUERY_DEFINITION_DISTRICT & 1 \\
\hline CONTRACT_ARCHIVE_BLOBS_3 & 1 & QUERY_DEFINITION_SYSTEM & 1 \\
\hline CONTRACT_ARCHIVE_TABLES_3 & 1 & QUERY_REQUEST & 1 \\
\hline CONTRACT_FILTER & 1 & RB_ITEM & 1 \\
\hline CONTRACT_GROUP & 1 & RB_ITEM_Q & 1 \\
\hline CONTRACT_INFO & 1 & RB_VIEWS & 1 \\
\hline CR_ATTACH & 2 & REAL_PRO & 1 \\
\hline CURRENT_REQUEST & 1 & RECORD_ATTACHMENT_CONTRACT & 3 \\
\hline CWE_MOD_LOG & 1 & RECORD_ATTACHMENT_DISTRICT & 3 \\
\hline DAILYLOG & 3 & RECORD_ATTACHMENT_OFFICE & 3 \\
\hline ERRORLOG & 2 & RECORD_ATTACHMENT_SYSTEM & 3 \\
\hline EX_LOG & 4 & RECORD_ATTACHMENT_USER & 3 \\
\hline FARS & 1 & RECORD_CLIENTREQUEST_CONTRACT & 2 \\
\hline FAST_REPORT_DISTRICT & 1 & RECORD_CLIENTREQUEST_DISTRICT & 2 \\
\hline FAST_REPORT_SYSTEM & 1 & RECORD_CLIENTREQUEST_OFFICE & 2 \\
\hline FEATURE & 5 & RECORD_CLIENTREQUEST_SYSTEM & 2 \\
\hline FEATURE_CK & 2 & RECORD_CLIENTREQUEST_USER & 2 \\
\hline FORM1354 & 3 & REPORT_CATEGORY & 1 \\
\hline FORM1413 & 1 & REPORT_PARAM & 1 \\
\hline FORM2626 & 18 & REPORT_RUN & 1 \\
\hline FORM2626_CCASS & 7 & REPORT_SCHEMA & 2 \\
\hline FORM2626_CCASS_LOG & 2 & REQUEST & 6 \\
\hline FRD & 1 & REVISION_HISTORY & 1 \\
\hline FRS & 1 & RFI_COE & 1 \\
\hline FRS197 & 1 & RFI_COE_ATTACHMENTS & 3 \\
\hline FRS199 & 1 & RFI_KTR & 2 \\
\hline FRSBKP & 1 & RFI_KTR_ATTACHMENTS & 3 \\
\hline GOV_DOCUMENT_STORE & 1 & RFI_REMARKS_SEC & 1 \\
\hline KTR_CLAIMS & 2 & RMS_FILES & 1 \\
\hline KTR_PAYROLL & 2 & RMS_FILES_CONTRACT & 1 \\
\hline KTR_PAYROLL_DUPS & 2 & RMS_FILES_OFFICE & 1 \\
\hline KTR_PAYROLL_GOV & 2 & SAFETY_EXPOSURE & 1 \\
\hline LABOR & 2 & SAFE_CK & 1 \\
\hline MOBILE_CONTRACT_MEDIA & 1 & SCHEMA_VERSION & 1 \\
\hline MOD_DOCS & 1 & SDEF_DATA & 1 \\
\hline MOD_LOG & 7 & SDEF_PROJECT_HISTORY & 4 \\
\hline NARRATIVES & 1 & SER_ATTACH & 3 \\
\hline OFFICE_ATTACH & 2 & SER_LOG & 1 \\
\hline OFFICE_PLAN & 1 & SHARE_DOCUMENT_STORE & 1 \\
\hline P2LINK & 3 & SPELLING & 1 \\
\hline P2LINK_MASTER & 3 & SPELLING_LIB & 1 \\
\hline PC_84A & 5 & SRPART & 3 \\
\hline PHASE & 2 & STAFF_INI & 1 \\
\hline PROJ & 3 & STAFF_WEBSTATE & 1 \\
\hline QATEST & 1 & STANDARDTEXT & 1 \\
\hline QCI_DAILYLOG & 3 & SUBMIT & 3 \\
\hline QCI_FEATURE & 5 & SYNC_CHANGESET & 1 \\
\hline QCI_QC_REQUIREMENTS & 2 & SYNC_INVOCATION_LOG & 1 \\
\hline QCI_SRPART & 3 & SYNC_TRANS_DETAIL & 1 \\
\hline QCI_SUBMIT & 3 & SYNC_TRANS_PACKAGE & 2 \\
\hline QCI_TRANSMIT_REMARKS & 1 & TMPWORD01 & 1 \\
\hline QCQA_COM & 1 & TRANSMIT_OFFICES & 1 \\
\hline QC_REQUIREMENTS & 2 & TRANSMIT_REMARKS & 1 \\
\hline QDD & 1 & TRANSMIT_REMARKS_CONTRACTOR & 1 \\
\hline QDS & 1 & TRANSMIT_REMARKS_SEC & 1 \\
\hline QUERY_DEFINITION_DISTRICT & 1 & WEATHER_DELAY_MONTH & 1 \\
\hline QUERY_DEFINITION_SYSTEM & 1 & WORD01 & 1 \\
\hline QUERY_REQUEST & 1 & WORDO1_BKP & 1 \\
\hline RB_ITEM & 1 & WORDO1_SAVE & 1 \\
\hline
\end{tabular}




\section{Acronyms and Abbreviations}

\begin{tabular}{|c|c|}
\hline API & Application Program Interface \\
\hline BIM & Building Information Modeling \\
\hline BLOB & Binary Large Object \\
\hline $\mathrm{CAD}$ & Computer Aided Design \\
\hline CLOB & Character Large Object \\
\hline DoD & Department of Defense \\
\hline EDW & Enterprise Data Warehouse \\
\hline ERDC & U.S. Army Engineer Research and Development Center \\
\hline ERSI & Environmental Systems Research Institute \\
\hline GB & Gigabyte \\
\hline IIS & Internet Information Services \\
\hline ITL & Information Technology Laboratory \\
\hline NCLOB & National Large Object \\
\hline PDT & Project Delivery Team \\
\hline PW & ProjectWise Explorer \\
\hline SQL & Structured Query Language \\
\hline URI & Uniform Resource Identifier \\
\hline USACE & U.S. Army Corps of Engineers \\
\hline
\end{tabular}




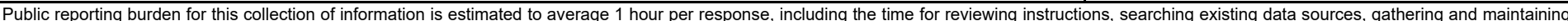

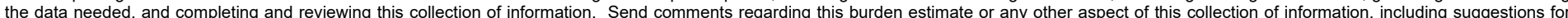

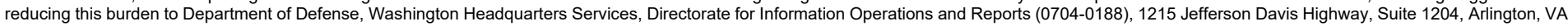

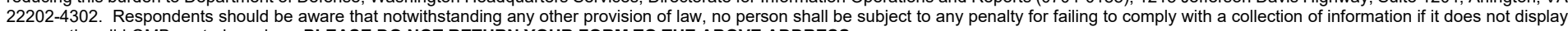
a currently valid OMB control number. PLEASE DO NOT RETURN YOUR FORM TO THE ABOVE ADDRESS.

\begin{tabular}{l|l|l} 
1. REPORT DATE (DD-MM-YYYY) & 2. REPORT TYPE & 3. DATES COVERED (FrOm - To)
\end{tabular}

September 2021

4. TITLE AND SUBTITLE

Final

Alternative Analysis for Construction Progress Data Spatial Visualization

5a. CONTRACT NUMBER

5b. GRANT NUMBER

5c. PROGRAM ELEMENT NUMBER

\section{AUTHOR(S)}

5d. PROJECT NUMBER

Jonathan L. Boone, Bobby Sells, Matthew Davis, and Dan McDonald

5e. TASK NUMBER

5f. WORK UNIT NUMBER

\section{PERFORMING ORGANIZATION NAME(S) AND ADDRESS(ES)}

Information Technology Laboratory

U.S. Army Engineer Research and Development Center

3909 Halls Ferry Road, Vicksburg, MS 39180-6199;

8. PERFORMING ORGANIZATION REPORT NUMBER

U.S. Army Corps of Engineers, Nashville District

U.S. Army Corps of Engineers

801 Broadway A415, Nashville, TN 37203

\section{SPONSORING / MONITORING AGENCY NAME(S) AND ADDRESS(ES)}

U.S. Army Corps of Engineers

Washington, DC 20314-1000

ERDC/ITL TR-21-5

\section{DISTRIBUTION / AVAILABILITY STATEMENT}

Approved for public release; distribution is unlimited.

\section{SUPPLEMENTARY NOTES}

CADD Military Direct Program Work Unit, FWIC:673KDK

\section{ABSTRACT}

This research was conducted to determine alternatives for migrating Resident Management System (RMS) data into a portal web viewer. This report provides proposed solutions to creating these links in efforts to better harmonize data management and improve project presentation. The U.S. Army Corps of Engineers (USACE) construction projects have multiple stakeholders that collaborate with project delivery team members during the execution of these projects. Many of these stakeholders are located across the U.S., which makes virtual interactions a common communication method for these teams. These interactions often lack spatial visualization, which can add complications to the progress reports provided and how the information is received/interpreted. The visualization of project progress and documents would be invaluable to the stakeholders on critical projects constructed by the USACE.

\section{SUBJECT TERMS}

Construction projects - Management

Project management

\section{SECURITY CLASSIFICATION OF:}

a. REPORT

Unclassified
b. ABSTRACT
Unclassified

Database management

Information visualization 